\title{
Hybridisation Potentials for Heavy Trucks Considering Route Topography
}

\author{
Oliver Zirn ${ }^{1}$, Stephan Krauth ${ }^{1}$ and Michael Ahlborn ${ }^{2}$ \\ 1. Automotive Engineering Faculty, Esslingen University of Applied Sciences, Esslingen 73728, Germany \\ 2. Institute for Process and Production Control, Clausthal University of Technology, Clausthal 38678, Germany
}

\begin{abstract}
Based on dynamometer test cycles or plain motorway operation, heavy truck hybridisation must be considered as uneconomic if only the kinetic vehicle energy can be recuperated. In mountainous regions, micro hybridization by a 48V-belt generator or mild parallel hybridisation by a large high voltage electric drive can result in considerable fuel consumption savings as well as additional benefits for heavy load utility vehicles. Additional electric power and battery size are still critical design parameters as well as critical cost factors considering the limited space and depreciation time as well as the need for maximum payload. Based on vehicle model simulations, this contribution quantifies fuel consumption savings, recuperation energy harvesting and battery requirements for different truck sizes with test cycles based on realistic route topography. The main route topography parameter for the recuperation benefit is the effective incline that integrates all downhill sections that overcompensates the vehicle resistance by tire friction and air resistance. The simulation parameter studies lead to an analytical benefit estimation, based on load cycle parameters like effective velocity, effective incline as well as the vehicle parameters mass, drag coefficient and cross sectional area. Thus, the return on investment can be assessed by an analytic rule of thumb, based on tracked cycles of existing vehicles.
\end{abstract}

Key words: Hybridisation, vehicle model, simulation, test cycles, route topography.

\section{Introduction}

Requirements for utility vehicles differ significantly from passenger cars. Productivity pressure is high and emissions are progressively restricted. The enormous mileage $(>750,000 \mathrm{~km}$ without considerable component exchange), comparatively small series and the huge number of options for different applications result in a challenging issue for the vehicle manufacturers. Successful hybridisation examples include city traffic busses due to the recuperation potential of the start-stop-operation and their ability to drive silently over short distances with electric power. Hybrid distribution van test fleets yield promising results too. Several hybrid light trucks for urban distribution traffic are presented as prototypes or even as acquirable options.

Corresponding author: Oliver Zirn, Prof. Dr. habil., research fields: truck electrification, modelling of automotive systems.
For heavy trucks above 12 tons, there are very few prototype studies. Existing regenerative braking options (e.g. for garbage trucks) use hydrostatic energy storage devices instead of batteries. One reason for the truck manufacturer's reluctance is the expected small fuel saving potential on a flat motorway or for a standardised dynamometer test cycle like the WHTC (World Harmonised Transient Cycle), as shown in Fig. 3 , based on a simulation with the vehicle model discussed in Section 2.

In Sections 3 and 4, the expected fuel saving potential for mountainous route topography depending on hybridisation grade and battery capacity is quantified. Several design examples elucidate the expectable hybridisation potentials for heavy load commercial vehicles in mountainous regions.

\section{Hybrid Truck Vehicle Model}

Due to the lack of suitable heavy load vehicle 


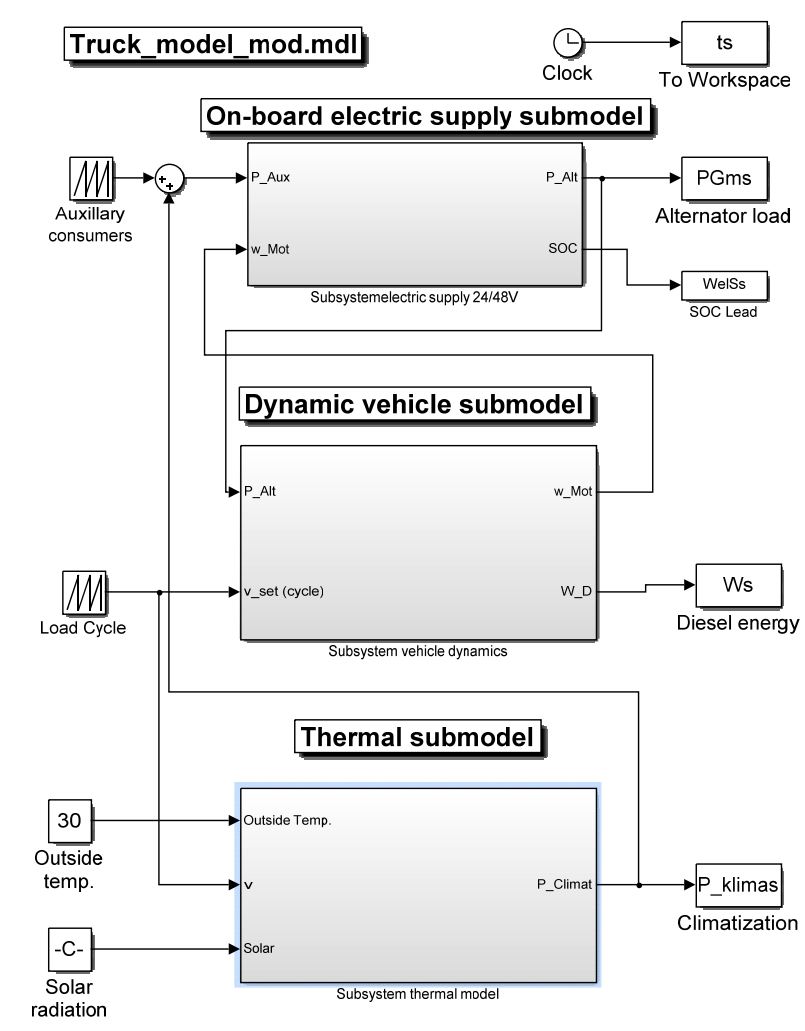

Fig. 1 Truck model structure.

prototypes, the only way to analyse the hybridisation benefit is the simulation of test cycles with a detailed vehicle model as shown in Figs. 1 and 2. This model had been developed from a well validated electrical passenger car model $[5,12,13]$ and was extended for heavy load commercial vehicles with parallel hybridisation. The fuel consumption model has been validated for diesel operated commercial vehicles in the mountainous Harz region, the Stuttgart area and for long distance motorway operation in Germany.

Although there has been a lot of research in hybrid vehicle control optimization also especially for diesel trucks (e.g. [1-4, 6-10]) with different optimization goals (fuel consumption, emission), hybridisation potentials can be quantified with a comparably simple (intuitive) control strategy:

- a professionally trained driver enables the hybrid controller to realize all braking operations with the electric drive train as long as the battery can store electrical energy (full regenerative braking) and the electrical braking power limit is not exceeded;
- the stored braking energy is afterwards used to drive the vehicle or to support the diesel engine until the battery is empty (no charge reserve for electric driving or combustion engine start);

- no diesel engine operation point optimisation in order to maintain a certain charge reserve;

- Plug-in-operation can be considered by a charged battery at the beginning of the test cycle simulation.

The dynamic vehicle submodel, the block diagram and the Simulink implementation is shown in Fig. 2. The force distribution between diesel motor, friction brake and electrical machine as well as the efficiency of the electric drive train (motor, power electronics, and battery) is calculated analytically for every integration step of the simulation. The efficiency of the diesel engine depends on the operation point as it is the case for the gearbox and the wheels. The model parameters for the truck model are given in Table 1.

Fig. 3 shows the hybridisation benefit of a 18-ton vehicle (truck 1 in Section 5) for mild hybridisation $\left(P_{E}\right.$ $=20 \mathrm{~kW}, W_{B}=1-2 \mathrm{kWh}$ ) simulated with the model in Fig. 2. The benefit for the diesel consumption is comparatively small. Simulation with an alternative commercial truck dynamics engineering tool (see Fig. 4) yields comparable results.

\section{Mountainous Region Test Cycle}

The benefit increases significantly for the route topography in mountainous regions like the Harz or the Stuttgart metropolitan region (see Fig. 5) [10, 12].

Figs. 5 and 6 show an exemplary distribution vehicle cycle from Vahingen via Leonberg, Böblingen and Stuttgart city traffic. This cycle is characterized by significant ascents and descents:

Similar cycles have been tracked and investigated in Lower Saxony between Göttingen, Goslar and Clausthal [12]. The fuel saving benefit is more significant due to the recuperation of potential energy that is one order higher than the kinetic truck energy. The comparison of the fuel consumption in Fig. 5 to the WHTC dynamometer test procedure in Fig. 3 shows 

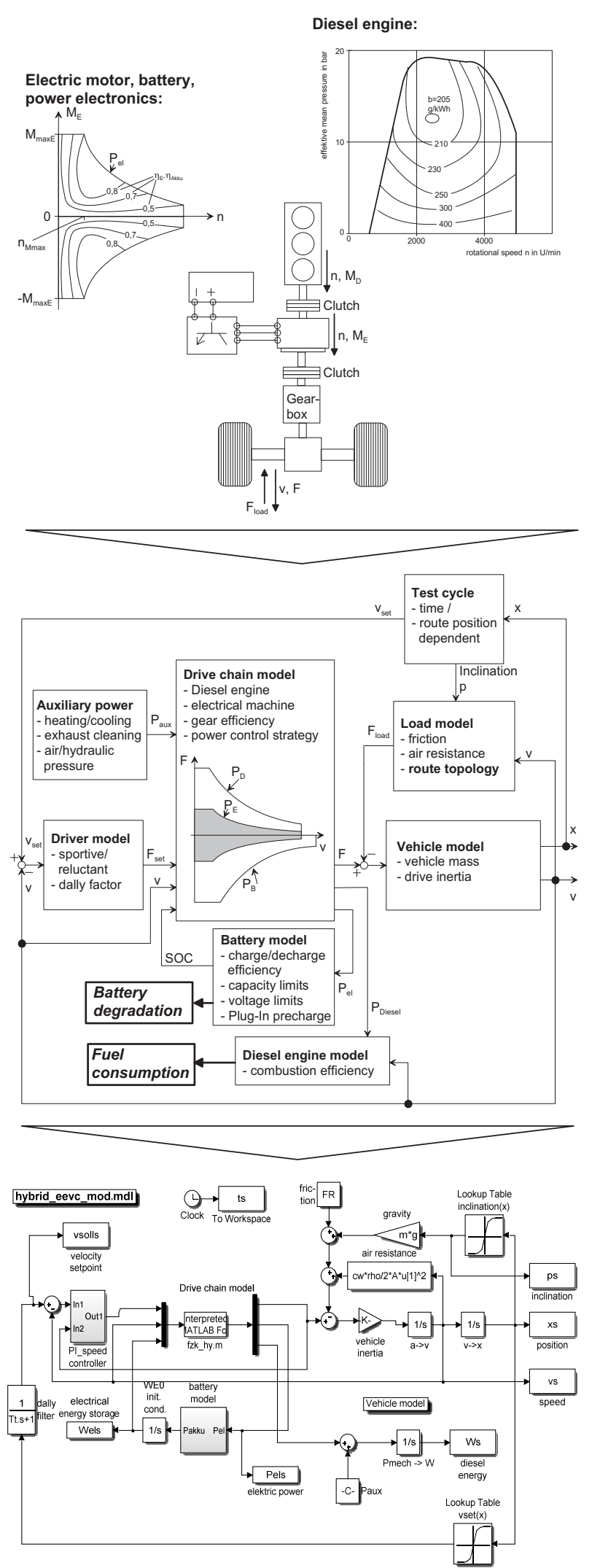

Fig. 2 Dynamic hybrid truck model (physical model, block diagram, Simulink implementation).
Table 1 Model parameters.

\begin{tabular}{ll}
\hline Parameter & Value \\
\hline Diesel engine power & $\mathrm{P}_{\mathrm{D}}=200 \mathrm{~kW}$ \\
Diesel engine efficiency & $\mathrm{B}=0.23 \mathrm{l} / \mathrm{kWh}$ \\
Gear chain efficiency & $\eta_{\mathrm{G}}=0.9$ \\
Maximum brake power & $\mathrm{P}_{\mathrm{B}}=250 \mathrm{~kW}$ \\
Electric machine power & $\mathrm{P}_{\mathrm{E}}=2-200 \mathrm{~kW}$ \\
Rated ohmic losses & $\mathrm{P}_{\mathrm{VE}}=0.05 \cdot \mathrm{P}_{\mathrm{E}}$ \\
Rated iron losses & $\mathrm{P}_{\mathrm{VFe}}=0.05 \cdot \mathrm{P}_{\mathrm{E}}$ \\
Rated motor speed & $\mathrm{V}=80 \mathrm{~km} / \mathrm{h}$ \\
Battery efficiency & $\eta_{\mathrm{B}}=0.92$ \\
Power electronics efficiency & $\eta_{\mathrm{PE}}=0.96$ \\
Auxillary power & $\mathrm{P}_{\mathrm{aux}}=1.5 \mathrm{~kW}$ \\
Tire friction factor & $\mathrm{f}=0.009$ \\
Vehicle mass & $\mathrm{m}=18-40 \mathrm{t}$ \\
Equivalent motor/gear mass & $\mathrm{m}_{\mathrm{M}}=0.15 \mathrm{~m}$ \\
Cross sectional area & $\mathrm{A}=6.6-8 \mathrm{~m}{ }^{2}$ \\
Air density & $\rho=1.3 \mathrm{~kg} / \mathrm{m}^{3}$ \\
Drag coefficient & $\mathrm{cW}=0.78$ \\
Proportional gain & $\mathrm{K}_{\mathrm{p}}=20 \mathrm{kNs} / \mathrm{m}$ \\
Integral time constant & $\mathrm{T}_{\mathrm{n}}=4 \mathrm{~s}$ \\
Dally low pass filter & $\mathrm{T}_{\mathrm{D}}=2 \mathrm{~s}$ \\
\hline &
\end{tabular}

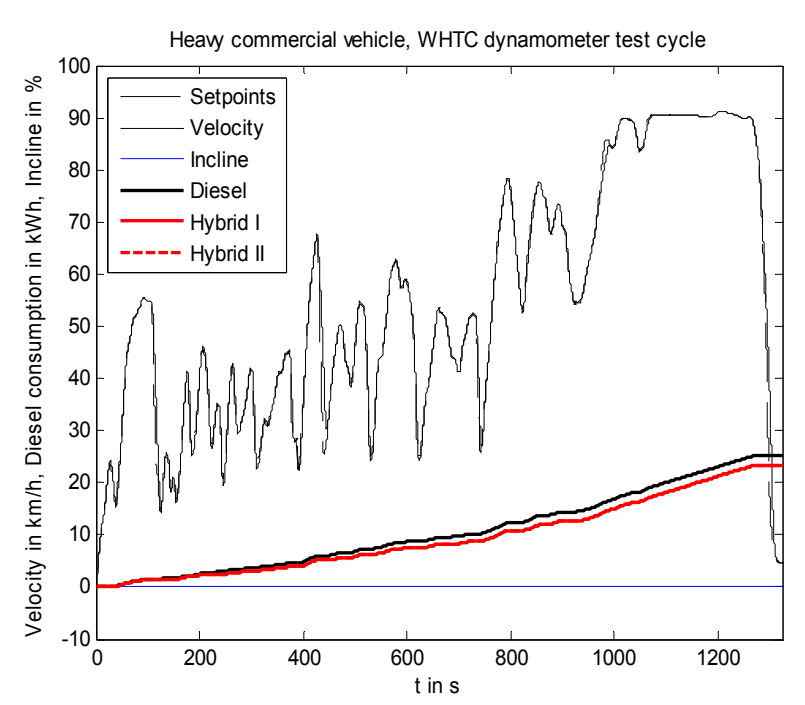

Fig. 3 WHTC dynamometer test procedure simulation results.

the additional hybridisation benefit if regenerative braking harvests kinetic as well as potential energy.

For a given route, the models in Figs. 2 and 4 allow an efficient design of the hybrid components (electric power, battery capacity). In Section 5, we discuss some examples for heavy load vehicles. 


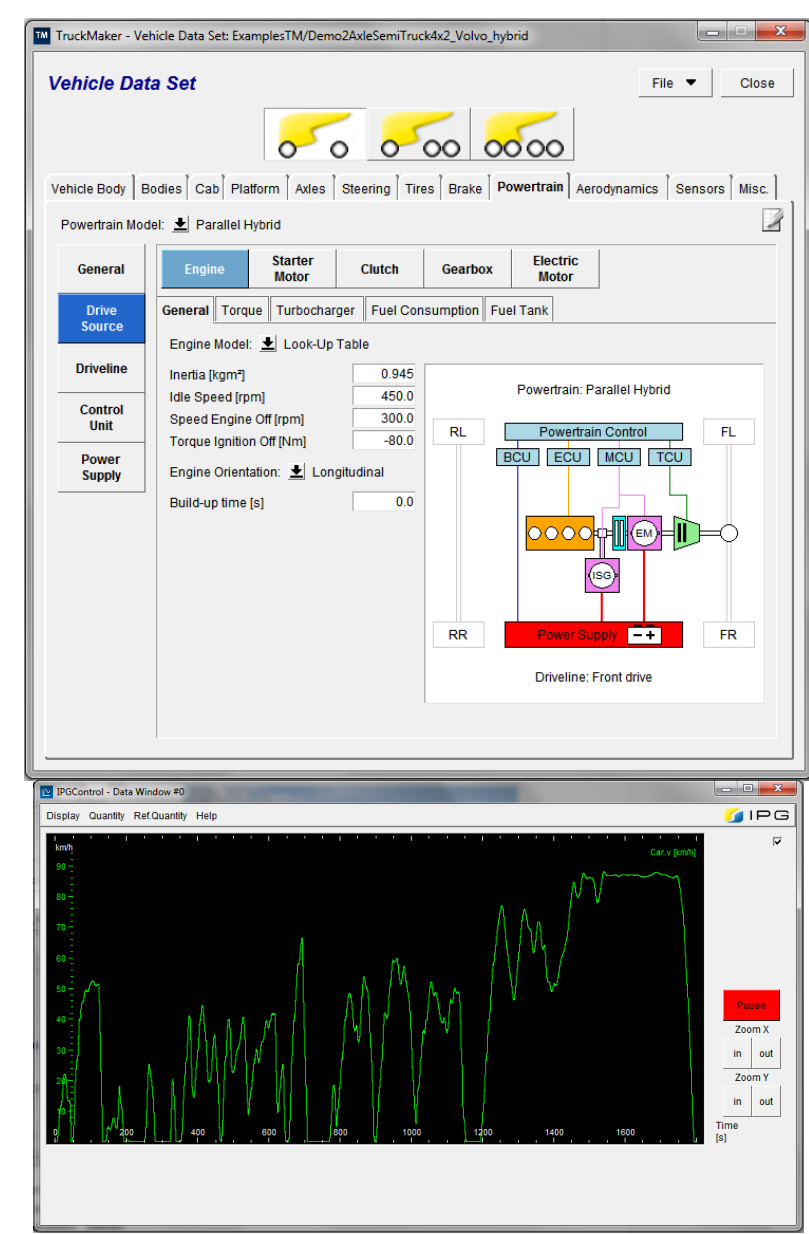

Fig. 4 Alternative truck model implementation with IGP TruckMaker ${ }^{\circledR}$.

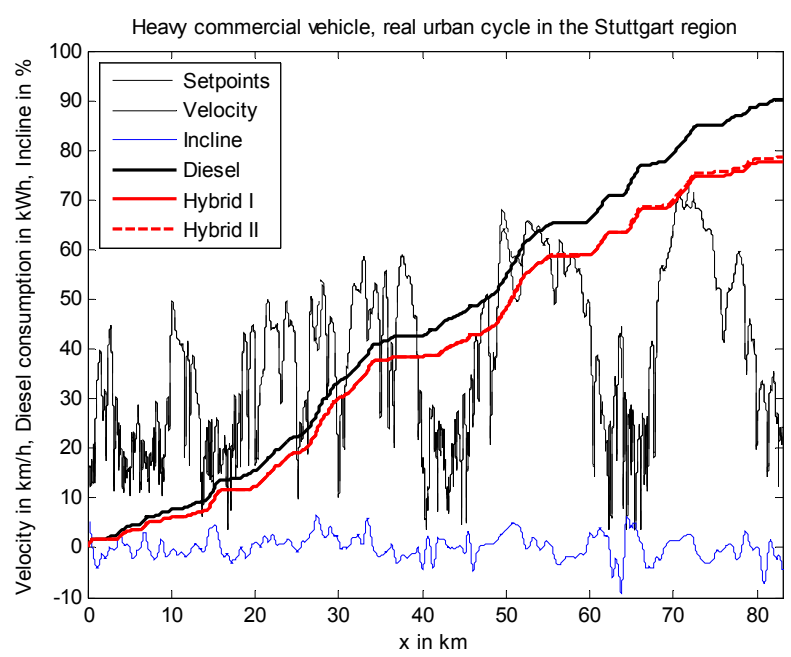

Fig. 5 Simulation results with the real driving cycle in the Stuttgart region including route topography.

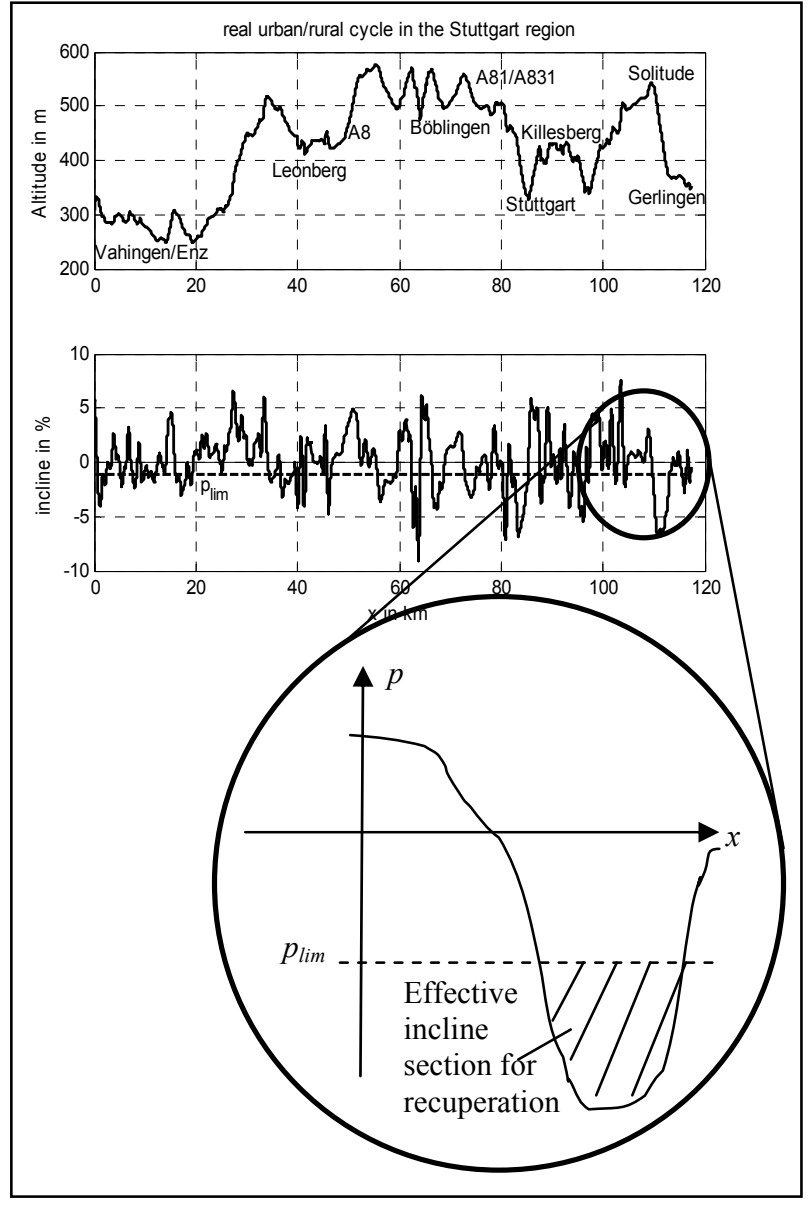

Fig. 6 Effective incline section for a heavy truck.

\section{Analytic Hybridisation Potential Estimation}

Although simulation is very helpful for the hybridisation potential assessment, it is restricted to universities and development departments. If a truck company/a hauler has to decide about the investment for a (more expensive) hybrid option, he needs an analytic estimation based on his exemplary routes, that can be implemented into an Excel-sheet or a vehicle configurator.

Based on various real driving cycles, we derived an analytical model to assess the fuel saving potential $b_{r e k}$, in litres on $100 \mathrm{~km}$ for full hybridisation (unlimited electric braking power and battery): 


$$
\left.\begin{array}{l}
b_{\text {rek }}{ }^{\prime}=b \cdot \eta_{G} \cdot\left(\eta_{M} \cdot \eta_{B} \cdot \eta_{P E}\right)^{2} \cdot m . \\
{\left[\begin{array}{l}
g \cdot \frac{c}{x} \cdot \int_{0}^{x}\left(p_{\lim }-p(\xi)\right) d \xi \text { for } p_{\lim }>p \\
0 \text { for } p_{\lim }<p
\end{array}+\frac{B E}{2} \cdot v_{\text {eff }}^{2}\right.}
\end{array}\right]
$$

with

$b$-diesel consumption per $\mathrm{kWh}$ at the combustion engine shaft (ca. $0.31 / \mathrm{kWh}$ )

$\eta_{\mathrm{G}, \mathrm{M}, \mathrm{PE}, \mathrm{B}}$-average efficiency of gearbox, electrical machine, power electronics and traction battery

$c$-reference distance $100 \mathrm{~km}=10^{5} \mathrm{~m}$

$x$ - test cycle distance or trip length

$p(x)$-route position dependent incline

$g$ - gravity constant

$m$ - truck mass

$B E$-number of brake events per $100 \mathrm{~km}$

The typical number $B E$ of brake events per $100 \mathrm{~km}$ for commercial vehicles is 400 to 600 in city traffic, 50 in rural operation and nearly zero on the motorway.

The effective drop height is the path integral over all sections below the recuperation incline limit. Smaller inclines can be retarded by friction and air resistance alone. Thus, the most relevant parameter for the hybridisation potential estimation is the inclination limit for potential energy recuperation, that is elucidated in the scope in Fig. 6:

$$
p_{\lim }=-\left(f_{R}+\frac{\rho \cdot c w \cdot A}{2 \cdot m \cdot g} \cdot v_{e f f}^{2}\right)
$$

with

$f_{R}$ - tire friction constant $(0.0085-0.011)$

- air density $\left(1.3 \mathrm{~kg} / \mathrm{m}^{3}\right)$

$c w$ - air drag coefficient (0.75-0.85 for trucks)

$A$ - cross section area (6-9 $\mathrm{m}^{2}$ depending on the truck $\mathrm{cab}$ and trailer geometry)

and the effective test cycle velocity

$$
v_{\text {eff }}=\sqrt{\frac{1}{T} \cdot \int_{0}^{T} v(\tau)^{2} d \tau}
$$

with the test cycle period $T . v_{\text {eff }}$ is higher than the average velocity that is typically indicated by route planners and navigation agents. Typical effective velocities for commercial vehicles are $25 \mathrm{~km} / \mathrm{h}$ in city traffic, $60 \mathrm{~km} / \mathrm{h}$ in rural operation and $80 \mathrm{~km} / \mathrm{h}$ on the motorway.

Effective velocity $v_{\text {eff }}$ and effective drop height $h_{\text {eff }}$ can be derived from representative test cycles, tracked by the hauler with his existing fleet. Also route planners for commercial vehicles can supply the data.

The analytical model according to Eq. (1) is a "best-case" estimation for full hybridisation. The expected benefit depending on the hybridisation grade is investigated in the following section.

\section{Examples}

Table 2 shows two exemplary heavy trucks with the actually available electric power range and the load cycle robust battery capacity that yields sufficient battery duration for $750,000 \mathrm{~km}$.

Table 3 shows the test cycle data of the two exemplary test cycles presented in this contribution. The fuel consumption $b$ ' has been specified by several inquired truck companies for real diesel trucks in the range of 18 to 40 tons to validate the truck model. The Stuttgart region test cycle is representative for rural/urban distribution vehicles. The motorways A81 and especially the A7 between Schweinfurt and Drammetal interchange are characterized by the highest inclines (up to $p=0.08$ !) in central Europe outside the Alps. Fig. 7 shows the fuel saving benefit $b_{r e k}$ for truck 1 depending on the installed electrical

Table 2 Heavy truck examples.

\begin{tabular}{lc}
\hline Parameter & Value \\
\hline Mass & Truck $1-18$ tons \\
Electric power & $m=18,000 \mathrm{~kg}$ \\
Battery capacity & $P_{E}=2-100 \mathrm{~kW}$ \\
\hline & $W_{B}<5 \mathrm{kWh}$ \\
\hline Mass & Truck $2-40$ tons \\
Electric power & $m=40,000 \mathrm{~kg}$ \\
Battery capacity & $P_{E}=2-200 \mathrm{~kW}$ \\
\hline
\end{tabular}


Table 3 Test cycles.

\begin{tabular}{ll}
\hline \multicolumn{1}{c}{ Parameter } & \multicolumn{1}{c}{ Value } \\
\hline Length & $x=117 \mathrm{~km}$ \\
Effective drop height & $h_{\text {eff }}=525 \mathrm{~m}$ \\
Effective velocity & $v_{\text {eff }}=34.3 \mathrm{~km} / \mathrm{h}$ \\
Effective incline & $p_{\text {eff }}=1.31-1.34 \%$ \\
Brake events on $100 \mathrm{~km}$ & $B E=50$ \\
Fuel consumption ${ }^{*}$ & $b^{\prime}=25 / 531 / 100 \mathrm{~km}$ \\
\hline \multicolumn{1}{c}{ A81/A7 test cycle $($ Stuttgart - Göttingen) } \\
\hline Length & $x=394 \mathrm{~km}$ \\
Effective drop height & $h_{\text {eff }}=437 \mathrm{~m}$ \\
Effective velocity & $v_{\text {eff }}=60.4 \mathrm{~km} / \mathrm{h}$ \\
Effective incline & $p_{\text {eff }}=1.01-1.08 \%$ \\
Brake events on $100 \mathrm{~km}$ & $B E=10$ \\
Fuel consumption ${ }^{*}$ & $b^{\prime}=26 / 511 / 100 \mathrm{~km}$ \\
\hline
\end{tabular}

*for pure diesel operation with $18 \mathrm{t}$ - and $40 \mathrm{t}$-trucks.

power $P_{E}$ on the Stuttgart region test cycle. With full hybridisation the estimated fuel saving according to Eq. (1) of about $15 \%$ can be reached. The maximum required capacity $W_{B}$ remains smaller than $2 \mathrm{kWh}$. As expected by Eq. (1), truck 2 doubles the fuel saving if more than $100 \mathrm{~kW}$ electric power is installed and the battery capacity exceeds 4 kWh (see Fig. 8). On the motorway test cycle shown in Figs. 9 and 10, the fuel saving is about $12 \%$ for full hybridisation. Due to the long route sections below the inclination limit $p_{\text {lim }}$ according to Eq. (3), the required battery capacity is about $10 \mathrm{kWh}$.

After having investigated several test cycles in mountainous regions as well as different sub-sections on these test cycles, we found a comparably simple rule of thumb to estimate the consumption saving $b_{\text {rek,est }}$ depending on the installed hybrid electrical power $P_{E}$ :

$$
b_{\text {rek, }, \text { est }}\left(P_{E}\right)=b_{r e k} \cdot \frac{\left(P_{E} / P_{E 0}\right)^{3 / 2}}{0.6+\left(P_{E} / P_{E 0}\right)^{3 / 2}}
$$

with the mild hybridisation rated power

$$
P_{E 0}=m \cdot g \cdot p_{e f f} \cdot v_{e f f}
$$

and the effective incline

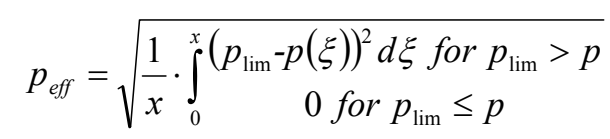

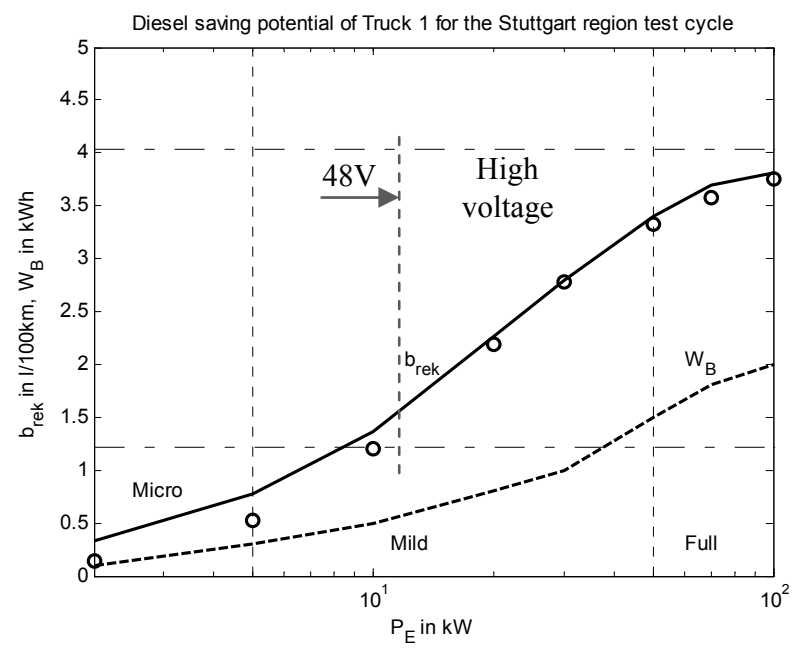

Fig. 7 Fuel saving potential and required battery capacity for truck 1 on the Stuttgart region test cycle.

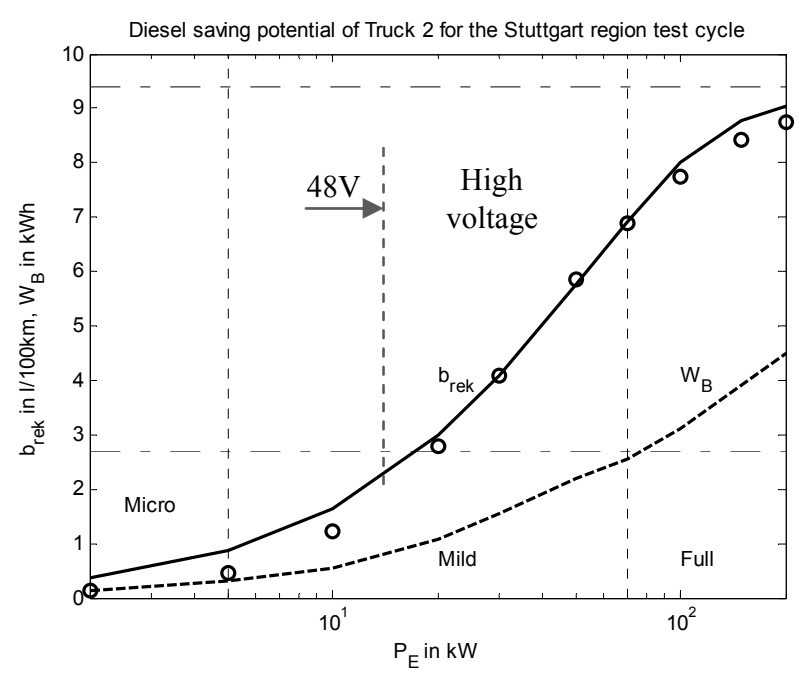

Fig. 8 Fuel saving potential and required battery capacity for truck 2 on the Stuttgart region test cycle.

The comparison of simulation results and the rule of thumb according to Eq. (4) (circles in Figs. 7-10) shows the reliability for hybridisation potential estimation. Especially for vehicle configuration agents and economic vehicle optimization, the rule of thumb can replace much more calculation power consuming simulations.

For Truck 1 mild hybridisation $\left(P_{E 0}=30 \mathrm{~kW}\right)$ results in a fuel saving potential of 2 to 3 litres per $100 \mathrm{~km}$ (see Figs. 7 and 9). Based on a diesel price of $1.1 € / 1$ the mild hybrid truck will save between $15,000 €$ and $25,000 €$ within the period of amortisation.

Actually, the leading driveline manufacturers are 


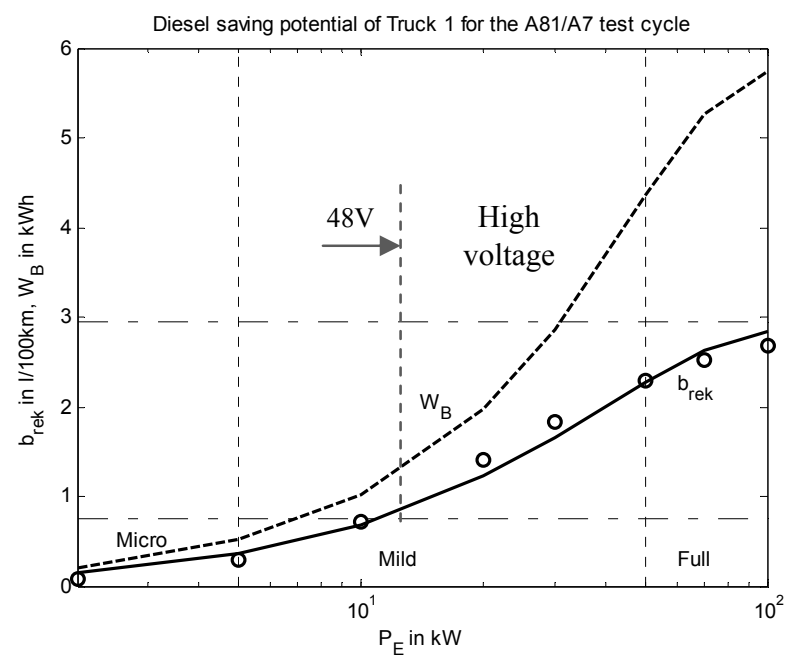

Fig. 9 Fuel saving potential and required battery capacity for truck 1 on the A81/A7 test cycle.

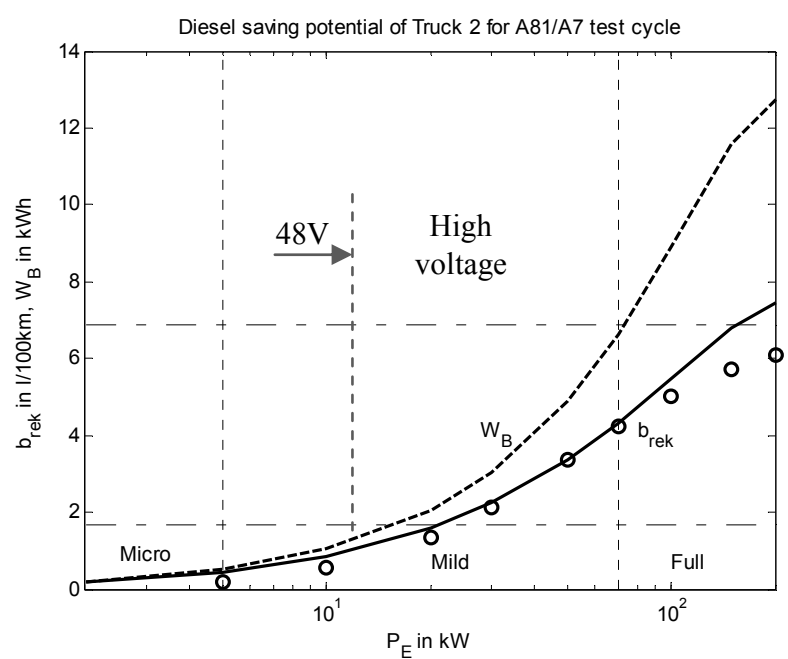

Fig. 10 Fuel saving potential and required battery capacity for truck 2 on the A81/A7 test cycle.

reluctant about the expected parallel hybrid options additional costs. But the actual purchase price of ca. $500 € / \mathrm{kWh}$ for modern robust LiFePO battery cells elucidates the fact that hybridisation of commercial vehicles is not necessarily blocked by component costs.

The application of $48 \mathrm{~V}$-on-board components from luxury-class passenger cars can be expected as first step into large scale truck hybridisation in the midterm. The increased generator power $\left(P_{E} \approx 10-12 \mathrm{~kW}\right)$ in combination with additional motor functionality (boost-operation) yields a theoretical fuel saving benefit of 1-2 1/100 km and requires a comparably small additional battery capacity of about $2 \mathrm{kWh}$ (see
Figs. 7-10). The real saving potential will be smaller due to the limited belt gear efficiency of a motor-generator-alternator, which produces significant losses (and wear) for recuperation as well as for boost-operation.

The alternative usage of the recuperation energy harvested on route parts with $p<p_{\text {lim }}$ in the truck electrical system is part of the actual applied research efforts.

\section{Conclusions}

Hybrid trucks have a considerable fuel saving potential in the range of $10 \%$ to $15 \%$ when operated in mountainous regions. The return on investment can be assessed by a simple analytic rule of thumb, based on tracked cycles and route topography of existing vehicles in the fleet.

Although additional electrical components (motor-generator, DCDC-converter) and especially the battery remain an important cost issue for hybridisation, it can be expected that micro- and later mild-hybridisation will reach a larger scale for modern trucks. In the foreseeable future, law enforcements for emission free city traffic or prestige advertising will overrule the pure cost analysis.

\section{References}

[1] Ambühl, D. 2009. "Energy Management Strategies for Hybrid Electric Vehicles." ETH Diss. Nr. 27302, Measurement and Control Laboratory, Swiss Federal Institute of Technology, Zürich.

[2] Back, M. 2005. "Prädiktive Antriebsregelung zum energieoptimalen Betrieb von Hybridfahrzeugen." Dissertation, Fakultät für Elektro- und Informationstechnik, KIT, Universitätsverlag Karlsruhe.

[3] Chan-Chiao, L., Huei, P., Grizzle, J. W., and Jun-Mo, K. 2004. "Power Management Strategy for a Parallel Hybrid Electric Truck." IEEE Transactions on Control Systems Technology 11 (6): 839-49.

[4] Frenkel, A., and Bruns, R. 2010. "Dezentrale optimale Betriebsstrategie für Hybridantriebe.” Logistics Journal DOI 10.2195, ISSN 2192-9084.

[5] Pelczar, C. 2012. "Mobile Virtual Synchronous Machine for Vehicle-to-Grid Applications." Dissertation, TU Clausthal, Cuvillier-Verlag, ISBN 9-783954-040643. 
[6] Riemer, T. 2011. "Vorausschauende Betriebsstrategie für ein Erdgashybridfahrzeug." Dissertation, Fakultät Konstruktions-, Produktions- und Fahrzeugtechnik, Universität Stuttgart.

[7] Stiegeler, M. 2008. "Entwurf einer vorausschauenden Betriebsstrategie für parallel hybride Antriebsstränge." Dissertation, Fakultät für Ingenieurwissenschaften und Informatik, Universität Ulm.

[8] Thiebes, P. 2011. "Hybridantriebe für mobile Arbeitsmaschinen.” Dissertation, KIT Karlsruhe, Karlsruher Schriftenreihe Fahrzeugsystemtechnik, Nr. 10.

[9] Kaszynski, M. 2013. "Prädiktions- und optimierungsbasierte Betriebsstrategie zur Realisierung des maximalen Einsparpotentials hydraulischer Parallelhybridfahr-zeuge.” Dissertation, Fakultät Konstruktions-, Produktions- und Fahrzeugtechnik, Universität Stuttgart.

[10] Van Keulen, T., De Jager, B., Serrarens, A., and Steinbuch,
M. 2010. "Optimal Energy Management in Hybrid Electric Trucks Using Route Information.” Oil \& Gas Science and Technology-Rev. IFP 65 (1): 103-13.

[11] Wenzl, H., Haubrock, A., and Beck, H.-P. 2013. "Degradation of Lithium Ion Batteries under Complex Conditions of Use." International Journal of Research in Physical Chemistry and Chemical Physics (Z. Phys. Chem.) 227: 57-71.

[12] Zirn, O., Ahlborn, M., Heyne, R., Ziegler, M., and Gabele, H., 2012. "Combining Heating and Range-Extension for Electric Vehicles." Presented at the European Electric Vehicle Conference (EEVC) 2012, Brüssel, Belgien.

[13] Zirn, O., Krauth, S., and Ahlborn, M. 2016. "Hybridisation Potentials for Heavy Trucks Considering Route Topography." Presented at the 7th IFAC Symposium on Mechatronic Systems \& 15th Mechatronics Forum International Conference, Loughborough University. 